\title{
1898, el fin de un ciclo de política mexicana en el Caribe
}

Laura Muñoz*

INSTITUTO MORA

\begin{abstract}
En las postrimerías del siglo XIX, el gobierno mexicano desplegó una hábil política para defender sus intereses nacionales ante los acontecimientos que ocurrieron en la región caribeña. El desenlace de la guerra hispanoestadunidense a favor de Estados Unidos obligó a México a retraer todas sus actividades en el Caribe.
\end{abstract}

\section{INTRODUCCION}

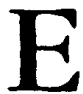

1 año 1898 cierra un largo periodo en que el interés de México por la región caribeña y en especial por Cuba fue constante. Durante todo el siglo XIX la región antillana fue para México una zona geográfica, estratégica, económica y política de significación. En su calidad de zona de frontera y región limítrofe -en que las potencias europeas tenían presencia y

* Agradezco el apoyo de Gabriela Pulido, Alejandro Álvarez y Gerardo Hernández por la búsqueda de información en los archivos. sobre la que Estados Unidos tenía ambiciones- el Caribe constituyó una preocupación para los gobiernos mexicanos, porque fue considerado uno de los espacios donde se definía la seguridad nacional, se resguardaba su territorio de amenazas externas y, por lo tanto, se defendía la soberanía. ${ }^{1}$

1 Siguiendo la documentación oficial, en este trabajo se considera al Caribe como la región insular que se extiende de la península de Florida a las costas de Venezuela así como el mar que la rodea. Con excepción de Belice -que fue dependencia de Jamaica hasta 1862 y compartía su carácter caribeño- no se incluyen los territorios continentales. 


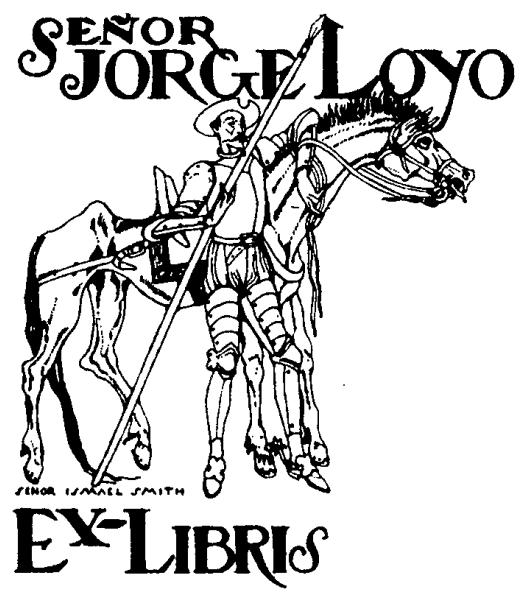

Para normar su conducta hacia esa región y procurar lo mejor para sus intereses nacionales, los gobiernos mexicanos desplegaron una hábil política basada en dos ejes. Por una parte, en la concepción de que la actitud de México hacia la zona respondía a la presencia de Europa y Estados Unidos en ella y, por otra, en la información abundante y detallada de lo que ocurría a nivel interno en las diferentes islas y en relación con los movimientos de las metrópolis que tenían colonias o interés en la región. Uno de los mejores ejemplos de esto lo encontramos al analizar la actitud de México hacia la independencia cubana en las postrimerías del siglo XIX. El presente trabajo, apoyado en la correspondencia consular, aborda este asunto situándolo en un contexto más amplio y no como un problema de relación bilateral entre México y Cuba.

\section{MÉXICO Y EL CARIBE}

Como es sabido, el litoral del Golfo -de gran extensión- era el medio más importante de acceso y salida de México; lo comunicaba a una zona geopolítica y a los grandes espacios de las rutas comerciales en las que tenía que colocar la exportación de sus productos. Era también, en el siglo pasado, el flanco más débil ante la amenaza extranjera y contenía una importante cantidad de entidades políticas compartiendo una superficie acuática. Esta situación obligaba a México a jugar una línea de política muy hábil hacia las metrópolis dueñas de colonias insulares, que podían movilizar tropas estacionadas en un espacio considerado como propio y contiguo a nuestro territorio, pero, paralelamente, con las islas, que aunque eran colonias de esas metrópolis también eran sociedades diferentes con desarrollos e intereses particulares. Para diseñar esa política, México tuvo en cuenta una serie de elementos, constantes unos y de naturaleza cambiante otros. Tenía que pensar en términos de la localización geográfica del territorio, en su tamaño y sus recursos, en la extensión de sus litorales y en el estado de su marina, en los intereses de las potencias europeas y, finalmente, en el mar como factor geopolítico por las relaciones económicas con otros países puesto que durante la mayor parte del siglo pasado, el mar fue el medio de transporte por excelencia. 
Sin recursos económicos y sin ambiciones expansionistas, a partir de la segunda mitad de ese siglo, México estableció una cadena de oficinas consulares y viceconsulares encargadas de recopilar información y de gravar parte del movimiento marítimo comercial que se dirigía al país. Sus representantes en la región desplegaron una actividad diplomática (en ciertos momentos) y consular (la mayor parte del tiempo), que respondió a una política defensiva respetuosa de los principios jurídicos que le dieron contenido y fuerza. ${ }^{2}$

A partir de finales de los años sesenta hubo en Cuba un consulado en La Habana y cuatro viceconsulados en diversos puntos de la isla: Matanzas (centro agrícola y segunda ciudad comercial de Cuba), Puerto Cárdenas (otro importante centro agrícola), Trinidad (escala en la ruta de Southampton a Veracruz) y Santiago (en el paso de las embarcaciones de Estados Unidos a América del Sur). Considerando el Caribe ampliado, el gobierno mexicano tenía oficinas viceconsulares en San Juan de Puerto Rico; Charlotte Amalie, capital de Santo Tomás; Kingston, en Jamaica; Belice (el único en tierra continental) y en Fort de France en la Martinica. Con esas oficinas cubría lugares estratégicos del arco antillano desde el punto de vista de la seguridad y del tráfico comercial, así como las islas que dependían de diferente metrópoli. En la mayoría de los casos, su instalación corrió a cuenta de ricos comerciantes locales que se com-

\footnotetext{
${ }^{2}$ He desarrollado más estas ideas en Muñoz, "Interés", 1996.
}

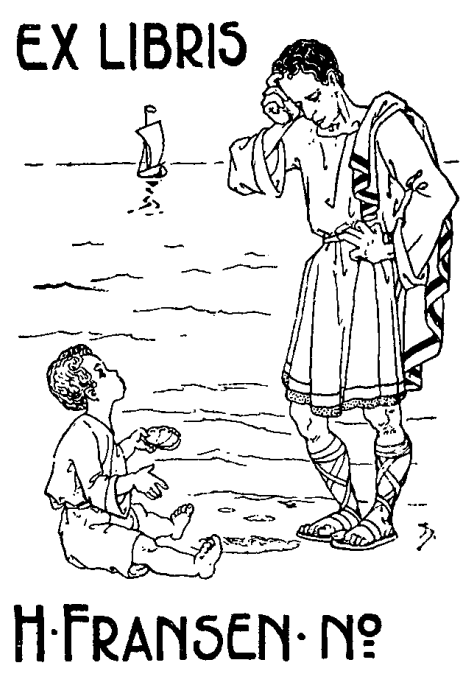

prometieron a enviar toda la información disponible acerca de la situación interna de las islas, donde fungieron como representantes de los gobiernos mexicanos, a cambio de retencr parte de las ganancias obtenidas por los trámites consulares. Si bien es cierto que la mayoría de esos representantes fueron comerciantes o estuvieron vinculados a las actividades mercantiles, varios de ellos tuvieron una cultura amplia y se dedicaron a otras actividades. Por ejemplo, uno de los cónsules en República Dominicana, José R. Abad, escribió una historia del país, ${ }^{3}$ otro en Santo Tomás, Juan Vilaró, era médico ${ }^{4}$

${ }^{3}$ Abad, República , 1888.

${ }^{4}$ Archivo Histórico de la Secretaría de Relaciones Exteriores de México (en adelante AHSREM), expediente personal, LE 1894 (VI), s.f. 
y en Haití, A. Jaegerhuber, era banquero. ${ }^{5}$ Además en ciertas representaciones, como en el consulado de La Habana, el puesto fue ocupado por gente formada en el cuerpo diplomático. ${ }^{6}$

La función primordial de esos consulados y viceconsulados era recabar información útil al gobierno mexicano para normar su conducta, razón principal por la que se mantuvieron a pesar de los informes desalentadores en cuanto al tráfico comercial entre las islas y México que no fue de proporciones considerables, pero aun en ese caso, se pretendía que se llevara a cabo

bajo las reglas establecidas por la ley, a fin de evitar hasta donde sea posible se falte a ella y se cometan irregulariclades abusivas que siempre refluyen en perjuicio de los intereses nacionales. ${ }^{7}$

Por la correspondencia de esas oficinas y la enviada por la Legación en Washington y el consulado en Nueva Orleans, así como en menor medida por las ubicadas en territorio francés o británico, las autoridades mexicanas estuvieron enteradas, en las últimas décadas del siglo XIX, de todo lo que ocurría en las Antillas, especialmente si amenazaba alterar la soberanía de los territorios, situación a la que no podía ser indiferente el gobierno mexicano que tenía "fundadas razones

' AHSREM, expediente personal, LE 1909.

' $\mathrm{El}$ caso más representativo fue Andrés C. Vázquez, véase AHSREM, LE 2218 (v) y exp. 40-2111 (I a VII).

7 Secretaría de Hacienda, 24 de octubre de 1877, AHSREM, exp. 44-20-173. para vigilar y estudiar esa clase de acontecimientos".

La documentación preservada nos ofrece información acerca de la venta entre metrópolis de sus posesiones coloniales, ${ }^{9}$ los movimientos armados en las islas y las medidas tomadas por los gobiernos como la ocupación de barcos que llevaban armas para los opositores,${ }^{10}$ sublevaciones,${ }^{11}$ cambios

${ }^{8}$ Vallarta a agente confidencial de México en Washington, México, 27 de marzo de 1878 , AHSREM, exp. 7-21-20, f. 2. Vallarta se halía enterado por la lectura de los recortes del Diario de la Marina, el Comercial Advertiser y el Courier des Etats Unis remitidos por los representantes de México en el exterior. En su carta al agente confidencial pide que le envíe los periódicos citados "acompañados con los informes y observaciones que usted juzgue convenientes para ilustrar su lectura" y al no recibirlos le pregunta si ha logrado obtenerlos. También solicita al cónsul en París "uno o dos ejemplares auténticos del tratado de cesión de la isla de San Bartolomé concluido entre Francia y Suecia, y aquellos artículos o revistas políticas en que ese acto haya sido explicado o comentado", quien se los envía al mes siguiente aclarando que San Bartolomé "dependerá, por decirlo así, de Guadalupe". Ibid., fs. 3 y 5 .

${ }^{9}$ Ibid.

${ }^{10}$ Matías Romero a I. Mariscal, Washington, 2 de noviembre de 1888, AHSREM, exp. 11-9199 , f. 12. La embarcación ocupada era un vilpor propiedad de ciudadanos estadunidenses quienes se quejaron a su gobierno y el Departamento de Estado solicitó un buque de guerra que se dirigiera a Puerto Príncipe con objeto de exigir la devolución del vapor. Pero poco después de haber llegado a Puerto Príncipe el primero, una fragata de guerra americana arribó y el capitán pidió que fuera puesto en libertad y amenazó con sacarlo a la fuerza si no lo dejaban continuar su camino. Unas horas antes de que expirara el plazo la embarcación fue puesta en libertad. Ibid., fs. 7-8.

${ }^{11}$ Matías Romero a I. Mariscal, Washington, 12 de junio de 1891, AHSREM, Archivo de la En- 
de gobierno, ${ }^{12}$ o su ratificación, ${ }^{13}$ apoyo a la población local en casos de violencia ${ }^{14}$ conflictos entre Dominicana y Haití, ${ }^{15}$ entre Haití y Alemania, ${ }^{16}$ la anexión de Dominicana a España, ${ }^{17}$ los asuntos internos en Puerto Rico, ${ }^{18}$ temas que eran complementados con otros recibidos a través de los informes de todas las oficinas. ${ }^{19}$ No faltaron en esas correspondencias los comentarios acerca de la opinión que merecía el régimen mexicano en la región, principalmente en Cuba. ${ }^{20}$ Tampoco

bajada de México en Estados Unidos (en adelante ABMEUA), t. 401 , fs. 576-578.

12 AHSREM, exps. 11-10-43 y 11-9-34.

${ }^{13}$ Ibid., exp. 11-8-108.

${ }^{14}$ Ibid,, exp. 11-9-34, y LE 1909. Véase también Romero a Mariscal, 21 de junio de 1891, AHSREM-AEMEUA, t. 401, fs. 710-711.

15 AHSREM, exp. 3-4-4094.

${ }^{16}$ AFiSREM-AEMEUA, t. 450, f. 445. Originada por la prisión del aleman Lüders, acusado de faltas a la policía. Una vez sentenciado solicitó ser nuevamente juzgado obteniendo una sanción mayor. E1 ministro alemán solicitó que fuera liberado y se le pagara una indemnización porque las pruebas eran a su favor. El gobierno de Haití se negó y el de Alemania envió a Puerto Príncipe al buque de guerra Kaiserin Augusta.

${ }^{17}$ AHSREM, exp. 1-2-390.

${ }^{18}$ Ibid., exp. 44-9-84.

${ }^{19}$ Por ejemplo, rumor acerca de una posible compra de Santo Domingo, Tratado de reciprocidad Estados Unidos-Haití, situación de Cuba, diferencias entre Santo Domingo y Haití, la comunicación Golfo-Caribe, Cuba y Estados Unidos, proyecto de anexión de Santo Domingo, Revolución en Haití, relaciones Estados UnidosSanto Domingo, situación en Puerto Rico, construcción del canal interoceánico, problemas limítrofes entre la Guyana inglesa y Venezuela. AHSREM-AEMEUA, tomos 146, 147, 150, 234, 253, $421,422,430,447$ y 448 entre otros.

${ }^{20}$ Archivo General de la Nación (AGN), ramo Gobernación y Relaciones Exteriores, Libro copiador de la correspondencia del Consulado de los informes netamente consulares donde se daba cuenta del movimiento marítimo de mercancías y personas, lo que se recaudaba en esas oficinas, la expedición de pasaportes, el contrabando y pesca ilícita practicada por las embarcaciones (viveros) cubanas, ${ }^{21}$ entre otros temas.

Por la cantidad de cartas y por el tono de los comentarios, podemos afirmar que una de las cuestiones que más preocupación causó fue la presencia estadunidense en la región ya fuera en referencia a la firma del 'Tratado comercial con España (que conllevaba implicaciones para Cuba) $;^{22}$ o del convenio de reciprocidad estadunidense con las Indias Occidentales ${ }^{23}$ o con el gobierno dominicano; ${ }^{24}$ a Hai$t^{1},{ }^{25}$ en donde se hablaba de la existencia de compromisos con el presidente Hippolyte; ${ }^{26}$ a República Dominicana,

México en La Habana correspondiente a los años de 1888-1889 [esta correspondencia en adelante se citará cono Libro copiador, años y la ubicación del documento citadol L(729.1-5)-15. Véase también Libro copiador, 1890-1891, L(729.1-5)-17.

${ }^{21}$ Libro copiador, 1897-1898, L(729.1-5)-23.

${ }^{22}$ Libro copiador, 1886-1887, L(729.1-5)-13.

${ }^{23}$ AHSREM-AEMEUA, t. 401.

${ }^{24}$ Matías Romero a I. Mariscal, Washington, 31 de mayo de 1891 , ibid., t. 401 , fs. $368-368 \mathrm{v}$.

${ }^{25}$ Matías Romero a I. Mariscal, Washington, 30 de enero de 1889, AHSREM, exp. 11-9-199, fs. 5 y $11-12$.

${ }^{26}$ Libro copiador, 1889-1892, L(729.1-5)-16. El cónsul en La Habana decía que se rumoraba que Hippolyte había ofrecido la cesión del muelle de San Nicolás, considerado "el Gibraltar de las Antillas", con lo que la posición de Estados Unidos en el áréa se fortalecía en el comercio y afectaba al resto de los países. Véase también AHSREM, exp. 11-9-199, fs. 15-16. En su correspondencia Vázquez señala que la guerra civil en Haití enfrentaba al expresidente Legitime, repre- 
por el proyecto estadunidense de ejercer un protectorado en ella o en alguno de sus puertos; ${ }^{27}$ la compra de Santo Tomás, para establecer una base naval $^{28}$ o la de Cuba, ${ }^{29}$ o su posible anexión a Estados Unidos, sin duda, la que más notas provocó. ${ }^{30}$ En una de ellas, el cónsul mexicano en La Habana, Andrés Clemente Vázquez, después de llamar la atención del secretario de Relaciones Exteriores, Ignacio Mariscal, diciéndole que mercantilmente Cuba era en realidad una factoría de Estados Unidos, le preguntaba si no sería conveniente que el gobierno mexicano tomara alguna medida al respecto. En esa ocasión terminó su carta comentando:

sentante de los intereses de Europa y, especialmente, de Francia y a Hippolyte, quien recibía ostensible apoyo de los cónsules y buques estadunidenses. bid., fs. 23-24, y M. Romero a I. Mariscal, AHSREM-AEMEUA, t. 401, fs. 576-578.

${ }^{27}$ Libro copiador, 1891-1892, L(729.1-5)-19.

${ }^{28}$ El cónsul Morón informa al respecto porque considera "que los acontecimientos políticos que vienen desarrollándose en algunas de estas Antillas en previsión de la apertura del canal interoceánico tienen, aunque indirectamente, cierta importancia para los intereses mexicanos tanto en el Golfo como en las repúblicas de Centroamérica [...]" Al parecer en un principio la compra de Santo Tomás sería en caso de que no se lograra la cesión de la bahía de Samaná. En opinión de nuestro cónsul era poco probable que los "señores yankees" lograran esa cesión "a menos que bajo el pretexto de un arrendamiento otorgado por el actual presidente, realicen ellos, más después, de facto la cesión"; esto porque España al retirarse de Santo Domingo se había reservado, por un tratado, el derecho de veto sobre la cesión a cualesquiera otra nación de la mencionada bahía. AHSREM, exp. 15-4-74 y exp. 15-8-11.

${ }^{29}$ Libro copiador, 1888-1889, L(729.1-5)-15.

30 Especialmente de Matías Romero desde Estados Unidos y de A. C. Vázquez desde Cuba.
Si debe o se puede hacer algo para impedir o no la anexión de Cuba a Estados Unidos, ese es asunto que está reservado exclusivamente a la perspicacia y patriotismo de nuestro gobierno. ${ }^{31}$

En las últimas décadas del siglo $\mathrm{XIX}$, el expansionismo estadunidense, además de invertir en los sectores productivos caribeños, puso mayor atención a la región por su ubicación en las rutas comerciales más importantes. Apoyado en los planteamientos de A. T. Mahan, ${ }^{32}$ consideró al Caribe como el espacio regional idóneo para establecer bases navales cuyo objetivo sería preservarlo de una amenaza europea y promover sus intereses militares y comerciales que se incrementarían con la eventual construcción de un canal en Panamá. En esa época, el Caribe además de ser importante para Estados Unidos lo cra para España porque una de sus colonias en la región, Cuba, contribuía de manera significativa a su economía. Para el resto de los viejos poderes europeos, el área caribeña había perdido la significación que tuvo en el pasado y aunque mantenían sus colonias, sus mayores intereses se ubicaban ya en otros lugares. ${ }^{33}$

Con la mayor presencia estadunidense en la región a través de sus inversiones económicas y sus ambiciones por mantener fuera de ella a todo poder europeo, unida a una serie de

${ }^{31}$ Libro copiador, 1887-1888, L(729.1-5)-12, reservada, f. 12. Sobre el tema de la anexión de Cuba a Estados Unidos, véase también, entre otros los tomos 16 y 17 de la misma serie.

${ }^{32}$ Mahan, Interest, 1918.

${ }^{33}$ Véase Muñoz, "Caribe", 1997, pp. 74-111. 
acontecimientos (entre los que se encuentran los intentos de adquisición de bahías estratégicas, transacciones metropolitanas para vender territorios coloniales, diferencias limítrofes, proyectos de construcción de un canal interoceánico, lucha de Cuba por su independencia), considerados por México como amenaza a su soberanía, el interés mexicano por el Caribe se renovó en los últimos años del siglo. A las oficinas existentes en Cuba (convertida en Consulado General), Santo Tomás y Martinica, se sumaron los consulados de Santo Domingo (que también adquirió el rango de General) y Puerto Príncipe, un viceconsulado en Puerto Plata; se restablecieron las oficinas de Kingston, Belice y San Juan, que habían cerrado temporalmente, y se firmó un tratado con República Dominicana ${ }^{34}$ Además de otras medidas posteriores como los intentos por mediar en el conflicto cubano español, ${ }^{35}$ ser observador en las cuestiones limítrofes entre Guyana y Venezuela ${ }^{36} \mathrm{o}$ recibir a grandes contingentes de fuerza de trabajo que no encontraban lugar en las islas, ${ }^{37}$ fueron parte del es-

\footnotetext{
${ }^{34}$ Tratado de amistad, comercio y navegación entre México y la República Dominicana. México, 29 de marzo de 1890 en Tratados, t. II, pp. 217-226.

35 Véase Rosenzweig, "Colonia", 1998, p. 8. El autor cita la correspondencia entre Telésforo García y Emilio Castelar.

${ }^{36}$ Véase sobre todo los Libros copiadores de la correspondencia de la legación de México en Wasbington, [en adelante se citará como Libros copiadores y la ubicación del documento citado] Archivo Matías Romero (AMR), Banco de México. (Una versión microfilmada se encuentra en el Instituto Mora).

${ }^{37}$ Muñoz, "Migración", 1996, pp. 77-90.
}

fuerzo mexicano para no perder presencia en el Caribe. ${ }^{38}$ Pero sin duda, el asunto que más interesó a México por esos años fue la independencia de Cuba que desembocó en la guerra hispano-estadunidense.

De la misma manera que el interés de España por la cuenca del Caribe incrementó la importancia de México por su situación geoestratégica respecto a Cuba como por su relativa importancia en el éxito de cualquier iniciativa conjunta latinoamericana, ${ }^{39}$ para México fue Cuba la que adquirió gran significación por su situación geoestratégica y por la importancia que le confería la presencia española en su suelo como un contrapeso al avance estadunidense. De hecho, como veremos más adelante, la simpatía mexicana por la causa independentista cubana se subordinó a la que se manifestó por España, y ambas a la defensa de los intereses nacionales. Para México era más conveniente la presencia española en la isla, pues no creía que siendo ésta independiente se mantuviera mucho tiempo libre de Estados Unidos. Sin embargo, cuando la causa española no se pudo sostener más en Cuba, México reivindicó con mayor fuerza la neutralidad que había adoptado oficialmente desde el restablecimiento de relaciones con España en los años setenta.

\footnotetext{
${ }^{38}$ Véase Muñoz, "Caribe", 1997.

${ }^{39}$ Sánchez, "Crisis", 1998, p. 7.
} 
CUBA Y MEXICO, DE LA GUERRA

DE INDEPENDENCIA A LA GUERRA

HISPANO-ESTADUNIDENSE, 1895-1898

La situación provocada por la independencia cubana en el último lustro del siglo XIX y la actitud mexicana respecto a ella, tanto a nivel oficial como popular, recuerda mucho lo ocurrido durante el intento emancipador anterior en la llamada guerra de los Diez Años. Igual que entonces, la simpatía popular se desbordó y la oficial se mantuvo en la neutralidad pero apoyando más a España ante la amenaza estadunidense que avanzaba sobre la región, en primer lugar a través de sus inversiones económicas y también con sus ambiciones de convertirse en el poder hegemónico en el Caribe. No obstante, en los noventa el desenlace fue distinto y México tuvo que abandonar, finalmente, su actitud de apoyo a la presencia española en Cuba.

Como se recordará, al reanudarse las relaciones entre México y España a finales de la década de los sesenta, en plena insurrección en Cuba, había quedado estipulado que México "se comprometía a cumplir con los deberes que le imponía el derecho internacional y a mantener estricta neutralidad con respecto a la isla antillana", aclarándose que esa neutralidad se llevaría a cabo de acuerdo a las leyes y en cuanto dependiese del gobierno, el cual solicitaba del español la abolición de la esclavitud. ${ }^{41}$ No obstante, siem. pre se mantuvo la creencia de que lo que ocurriera en la isla podía afectar a

\footnotetext{
${ }^{40} \mathrm{Pi}$-Suñer, México, 1985, p. 44.

${ }^{41}$ AHSREM, LE 1412, fs. 80-86, cit. en ibid.
}

la soberanía mexicana, bien fuera que se apoyara porque era "el más seguro afiance de nuestra independencia" 42 o porque si los estadunidenses la ayudaban, "la anexión sería inevitable y $[\ldots]$ sería fatal para nosotros". ${ }^{43}$ A partir de entonces, encontramos simpatía por los intentos de independencia cubana pero sin que el gobierno llegara a romper la neutralidad pactada con España, actitud, por cierto, criticada en la prensa en los siguientes términos:

México debe volver a tomar parte en esa lucha. No hablo del México oficial; nada nos importa esa cobarde hipocresía de la diplomacia: el pueblo es el que debe lanzarse a ayudar a sus hermanos, porque sus sentimientos no se norman por esas mentidas reglas del dolo que se llama derecho internacional. ${ }^{44}$

Paralelamente a esa simpatía mostró, en otros momentos, un apoyo evidente a España como única alternativa al empuje estadunidense que amenazaba con romper el orden regional, tomar la gran Antilla y provocar el cierre del Golfo convirtiéndolo en un lago americano.

Una vez iniciado el conflicto en la isla, en febrero de 1895, y hasta que estalló la guerra entre Estados Unidos y España en 1898, el gobierno mexicano puso en marcha varias estrategias que fueron, desde la difusión en el exterior de su posición neutral a través de sus

${ }^{42}$ Guillermo Prieto en El Monitor Republicano, 2 de diciembre de 1868, cit. en ibid., p. 79 .

43 Ibid.

${ }^{44}$ Hilarión Frías Soto, El Siglo $X I X, 14$ de diciembre de 1868, cit. en ibid., p. 80. 
representantes, campañas de prensa permitiendo que se defendiera una Cuba mexicana o una Cuba española, el apoyo a los independentistas cubanos, el ofrecimiento de mediación a España y el acercamiento a Estados Unidos. Sin embargo, el conjunto de la documentación revisada nos permite afirmar que la posición adoptada por México fue de simpatía activa hacia España encubierta por una declaración oficial de neutralidad. ${ }^{45}$

Veamos a continuación cómo se trataron esos temas en la correspondencia consular. De hecho, sin recurrir a otras fuentes se puede seguir el desarrollo de la insurrección misma, al principio vista por nuestro cónsul en La Habana, A. C. Vázquez, como una revuelta más que sería rápidamente sofocada, pero posteriormente evaluada en toda su dimensión, es decir, como una guerra interimperial que reflejaba el primer paso del ascenso estadunidense como poder regional, y que fue minuciosamente retratada con todos sus cambios y desenlaces en la correspondencia enviada al canciller en México por los representantes en el extranjero, principalmente, por Matías Romero en Estados Unidos y por Vázquez en Cuba.

Don Andrés Clemente Vázqucz, en sus largas y detalladas cartas, escritas constantemente -una o varias al día y

\footnotetext{
45 Para otros acercamientos al tema véase Gilmore, "Mexico", 1963, pp. 511-525; Deger, "Porfirian", 1979; Muñoz, "México", 1998, Muñoz, "Política", 1998; Muñoz, "Caribe", 1997. Asimismo los trabajos de Bobadilla, "Opinión", 1994; Pulido, “Aproximaciones", 1997; Espinosa, "Caribe", 1997; Rojas, "Política", 1996, pp. 783-805, y Morales, Espacios, 1997.
}

en gran parte reservadas ${ }^{-46}$ incluían información general, noticias acerca de los insurrectos, sus avances o negociaciones al interior y exterior de la isla, algunas opiniones de la población, e intercalaba en su redacción sus consideraciones personales y sus sugerencias a la Secretaría. Acompañaba su correspondencia con mapas y datos interesantes para la Secretaría de Guerra -relativas por ejemplo a la defensa submarina de la isla o a la vigilancia militar de sus costas- y con reportes económicos. Además, consideraba parte de su obligación poner al tanto al Secretario de Relaciones Exteriores de los rumores que circulaban en Cuba ${ }^{47}$ En muchas de sus prolijas cartas reseñaba todo lo que las autoridades españolas ordenaban.

Matías Romero dividía sus comunicados en cartas y misceláneas. ${ }^{48}$ Las primeras, escritas con asiduidad, podían ser ordinarias o reservadas. En ellas hablaba de asuntos generales acerca de la insurrección, de las actividades de los cubanos en Estados Unidos, sus gestiones, las conversaciones que tenía con ellos y con el cuerpo diplomático, pero, sobre todo, informaba minuciosamente de las sesiones del Congreso estadunidense ${ }^{49}$ y de sus

\footnotetext{
${ }^{46}$ Más de 20 volúmenes en el AHSREM y más de diez en el AGN.

${ }^{47}$ A. C. Vázquez a I. Mariscal, 28 de enero de 1895, AHSREM, LE 517, fs. 47-53.

49 Varios volúmenes contenidos en AHSREMAEMEUA

49 En el que con asiduidad se debatía el reconocimiento de la beligerancia de los cubanos, la anexión de la isla $y$, desde la segunda mitad de 1897 , la posibilidad de la intervención armada. Véanse las cartas de Romero, de 1897 y 1898, AHSREM, LE 529.
} 
resoluciones respecto a los asuntos cubanos, acompañando sus notas con ejemplares de los Congressional Records. En las misceláneas, redactadas semanalmente, al lado de breves reportes sobre ciertos temas obligados, comunicaba lo más relevante de lo publicado en los periódicos estadunidenses en relación con los asuntos cubanos y enviaba relatos resumidos sobre las operaciones de guerra.

En sus reportes, Romero presentaba las noticias de Cuba según la versión española y según la de los particulares que disentían de la visión optimista del gobierno metropolitano. También se refería a las expediciones filibusteras, a la prohibición de publicar noticias que no procedieran de fuentes oficiales y escribía acerca del gobierno provisional de los insurrectos. ${ }^{50}$

En sus notas Vázquez se mostraba parco en sus opiniones sobre la insurrección y su futuro. En la mayoría de sus escritos no encontramos comentarios personales al respecto. En realidad, sus esfuerzos estaban encaminados a no comprometer a su gobierno cuidando la expresión de su pensamiento y limitándose a transmitir con detalle todo lo que sabía acerca de los movimientos de los independentistas. Otros eran los temas en los que se permitía abundar, como por ejemplo, en la amenaza estadunidense y en las medidas que debería tomar México. Nuestro cónsul en La Habana se cuidó mucho de expresar sus opiniones verbalmente y sólo lo hacía en círculos de

\footnotetext{
${ }^{50}$ Correspondencia reservada, Misceláneas, Sublevación en Cuba, AHSREM-AEMEUA, t. 437.
}

confianza. Matías Romero, en cambio, manifestó más abiertamente sus simpatías hacia el movimiento independentista en su correspondencia personal con Pedro Santacilia o con el cónsul mexicano en Chile, ${ }^{51}$ pero tampoco lo hacía en público por la posición oficial que ocupaba.

Ambos acompañaban sus informes con recortes de periódicos locales que contenían las noticias de "las operaciones", según las calificaba Matías Romero, o de los "sucesos de la guerra", como decía Vázquez. El primero enviaba carpetas con las notas de los periódicos estadunidenses y el segundo incluía las de periódicos habaneros, españoles y americanos. En general, enviaban información sobre los mismos temas, pero Vázquez era más extenso en relación con lo que ocurría en Cuba y enviaba recortes de otras noticias entre las que se encontraban algunas actividades de los senadores en el Congreso estadunidense relacionadas con la cuestión cubana, mientras Romero ponía el énfasis en estas deliberaciones, en las declaraciones del presidente y en sus entrevistas con el secretario de Estado o con los senadores que formaban la subcomisión de Relaciones Exteriores del Congreso y resumía aquellas noticias que procedían de la isla.

En varias cartas, Romero señaló su escepticismo a que el gobierno español pudiera poner en práctica medidas conciliatorias y resolver la situa-

\footnotetext{
51 Por ejemplo, Romero a Pedro Santacilia, 16 de diciembre de 1896, AMR, Libros copiadores, t. 59, f. 189, y Romero a José Alonso, 2 de abril de 1897 , ibid., f. 367
} 
ción cubana. ${ }^{52}$ Le parecía que todo se perfilaba para que Estados Unidos se apoderara de la isla, ${ }^{53}$ incluso, utilizando pretextos como el humanitarismo desatado frente a las medidas represivas impuestas por el capitán general de Cuba, Valeriano Weyler. ${ }^{54}$ En sus comentarios sobre los designios estadunidenses, Romero, aunque los identificaba, se mostraba menos crítico que Vázquez quien los veía como un peligro serio para México. ${ }^{55}$

En diversas cartas Romero reconoce el interés expansionista de Estados Unidos, no sólo de su gobierno sino también de ciertos sectores sociales. Se mostraba convencido de que la guerra con España era inevitable y que daría como resultado final la anexión de la isla a Estados Unidos, con las consecuentes repercusiones negativas para América Latina en general, pero, principalmente, para México. ${ }^{56}$

En cuanto al discurso de Vázquez, éste fue cambiando de tono a lo largo de su correspondencia. Hay notas en las que consideraba que México podía ir al unísono con Estados Unidos "a la cabeza de las naciones americanas", 57

\footnotetext{
52 Por ejemplo, Romero a I. Mariscal, 31 de diciembre de 1897, AHSREM, LE 529, fs. 108-109.

${ }_{53}$ Véase toda la correspondencia de esos años y en especial con Pedro Santacilia, AMR, Libros copiadores, t. 59 , fs. $155,708,771,937 \mathrm{y}$ 954.

${ }^{54}$ Romero a Mariscal, 15 de febrero de 1896 , AHSREM-AEMEUA, t. 439, f. 420.

ss A. C. Vázquez a I. Mariscal, reservada, 8 de febrero de 1897, AHSREM, LE 523.

${ }_{56} \mathrm{M}$. Romero a I. Mariscal, 7 de mayo de 1898, AHSREM, LE 530, fs. 98-99.

${ }^{57}$ A. C. Vázquez a I. Mariscal, reservada, 3 de diciembre de 1895, AHSREM, exp. 42-2111(III), fs. 157-158.
}

en otras, que debía temer esa presen$\mathrm{cia}^{58} \mathrm{y}$ hay algunas en las que aconseja disputarle un lugar. ${ }^{59}$ En enero de 1896 opinaba que la "soberanía espanola en Cuba y Puerto Rico corría gravísimo peligro de tocar a su término". ${ }^{6}$ Pocos meses después consideró que la intervención estadunidense para pacificar la isla no tardaría y el resultado sería la anexión de Cuba. ${ }^{61}$

Matías Romero era más reservado y sus consejos se presentaban de manera velada, recomendando siempre prudencia y esperar para saber lo que hacía Estados Unidos, mientras que los consejos de A. C. Vázquez eran directos y no tenían más encubrimiento que ir intercalados entre párrafo y párrafo de sus informes a la cancillería acerca de los acontecimientos cotidianos en la isla. Su posición fuc más "agresiva" y de proyección de México al que consideraba un poder que podía contender un lugar a los otros que existían en la región. Lo veía como una más de las potencias.

En los primeros meses de 1898 los dos representantes expresaron en sus comunicaciones la inminencia de la intervención de Estados Unidos y el desenlace bélico con España. Cuando éste ocurrió, ambos dedicaron gran parte de su correspondencia a transmitir toda la información disponible.

58 Véase AHSREM, LE 525.

"9 A. C. Vázquez a I. Mariscal, 24 de mayo de 1897 , ibid., LE 523, f. 44 y 2 de marzo de 1896 , ibid., LE 518 , fs. 7-8.

${ }^{60}$ A. C. Vázquez a I. Mariscal, 6 de enero de 1896, ibid., LE 532, fs. 87-95.

${ }^{6}$ A. C. Vázquez a I. Mariscal, 8 de junio de 1896, ibid., LE 521, f. 46. 
El tema del reconocimiento de beligerancia a los insurrectos cubanos fue uno de los que causó más inquietudes en el periodo estudiado. En México existía el precedente de la resolución del Congreso en 1869, que reconoció ese carácter a los cubanos involucrados en el proceso emancipatorio en la llamada guerra de los Diez Años, pero asimismo, en la contraparte estaba el antecedente de que el gobierno mexicano al final no había hecho efectivo ese reconocimiento por los acuerdos tomados para reanudar relaciones con España ${ }^{62}$ En esta ocasión tampoco le interesaba a México tomar una posición definida a favor de los cubanos, cuando sus intereses concordaban más con la presencia española en la isla.

Tanto Romero como Vázquez, continuaron el debate en torno al tema del reconocimiento o no de la beligerancia de cubanos a lo largo de 1895 1897 , reportando todo lo que se publicaba o discutía en los círculos políticos que observaban. En este asunto, la visión de los encargados mexicanos en Estados Unidos y en Cuba fue diferente. Al principio, Romero se limitaba a transmitir lo que se publicaba en Estados Unidos, pero en los primeros días de octubre de 1895, siguiendo las instrucciones que le comunicó la Secretaría, se movilizó para desmentir los rumores acerca del reconocimiento mexicano ${ }^{63} \mathrm{y}$ afirmar, posteriormente, que "México no tomaría la iniciativa en ese reconocimiento". ${ }^{64}$ Del conjun-

\footnotetext{
62 Pi-Suñer, México, 1985, pp. 46-47.

${ }^{63}$ Romero a I. Mariscal, 5 de octubre de 1896, AHSREM-AEMEUA, t. 437 , f. 30

${ }^{4}$ Romero a I. Mariscal, 21 de noviembre de 1895, ibid., t. 438, f. 400.
}

to de notas enviadas, podemos concluir que Romero creía que correspondía a Estados Unidos encabezar esa iniciativa ${ }^{65}$ Para Vázquez era un tema de gran incertidumbre. Él opinaba que sería arriesgado que el gobierno mexicano reconociera la beligerancia de los insurrectos cubanos, ${ }^{66}$ pero esperaba los comentarios de la Secretaría al respecto. Paralelamente, enviaba toda la información que sobre ese asunto circulaba en La Habana.

Durante el primer año del conflicto, Mariscal, hizo saber a Ios representantes mexicanos que el gobierno no estaba en disposición de reconocerles a los insurrectos el carácter de beligerantes. ${ }^{67}$ En 1896, el encargado de la Secretaría no hizo ningún comentario que pudiera servir de guía a nuestro cónsul en La Habana en cuanto a si se daría o no el reconocimiento ${ }^{68}$ más bien pidió a Romero que lo mantuviera al tanto de todo lo ocurrido en Estados Unidos relativo a ese asunto y, si es posible, informara, con la conveniente anticipación "si llegara a resolverse que el gobierno de Estados Unidos reconociera dicha beligerancia, comunicándolo por telégrafo sin perjuicio de hacerlo con pormenores por el correo", petición que Romero cumplió, no sin antes consultar con el secretario Olney, quien confirmó

\footnotetext{
${ }^{65}$ Romero a I. Mariscal, 17 de junio de 1897 , AHSREM, LE 529, fs. 70-71.

${ }^{66}$ A. C. Vázquez a I. Mariscal, 6 de diciembre de 1895, ibid., LE 515, fs. 168-172.

67 Mariscal a Romero, 20 de septiembre de 1895, ibid., LE 528, fs. 11-13.

${ }^{68}$ A. C. Vázquez, 18 de marzo de 1896 , e I. Mariscal, 30 de marzo de 1896, ibid., LE 519, fs. $23-25$.
} 
sus apreciaciones de que Estados Unidos no reconocería el carácter de beligerantes a los cubanos. ${ }^{69}$

Frente al tema de Cuba mexicana nuestros representantes tuvieron también actitudes distintas. ${ }^{70}$ Matías Romero fue el primero que envió recortes de la prensa estadunidense informando del proyecto. ${ }^{71}$ Transcribía todo lo que se publicaba al respecto en los periódicos estadunidenses y cómo lo tomaba la opinión pública (favorablemente, según él) ${ }^{72}$ Cuando se trataba de dar su opinión personal, mostraba en general, que no debería dársele importancia al asunto; con esos lineamientos escribía a Mariscal y pareciera que ésa fue la razón por la cual no lo comentó en su asidua correspondencia con Díaz, a diferencia del enviado y ministro plenipotenciario en España, el general Vicente Riva Palacio. ${ }^{73}$

\footnotetext{
${ }^{69}$ Mariscal a Matías Romero, 18 de enero de 1896, AHSREM-AEMEUA, t. 442, f. 81.

${ }^{70}$ En junio de 1895 habia empezado a circular en La Patria, periódico de la capital mexicana la propuesta de anexar Cuba a México como una solución a la crisis que enfrentaba. A los pocos meses fue secundada por una campaña de El Nacional. Véase Espinosa, "Proceso", 1996, y Muñoz, "México", 1998.

${ }^{71}$ Romero a Mariscal, reservada, 7 de septiembre de 1895 , AHSREM-ARMEUA, t. 437, f. 382, y Mariscal a M. Romero, 10 de octubre de 1895 , AHSREM-AEMEUa, t. 441, f. 307 . El Secretario aprueba que Romero no de importancia a las opiniones en relación a la Cuba mexicana y al interés expansionista de México, según fue publicado en la prensa estadunidense.

${ }^{72}$ Véase la correspondencia de Romero de septiembre y dicienbre de 1897, AHSREM, LE 529 , fs. 93-94, entre otras $y$ AHSREM-AEMEUA, ts. 437 y 441.

${ }^{73}$ Véase Colección Porfirio Díaz (en adelante CPD), legs. XX, XXI, XXII y XXIII.
}

Pero sí escribió al secretario de Guerra, Felipe Berriozábal, para informarle que el mensaje de diciembre de 1896 del presidente estadunidense contenía "conceptos importantes para nosotros", como aquél de que Estados Unidos no consentiría que Cuba se anexara a ninguna otra nación. ${ }^{74}$ No habiendo otra propuesta en esos días, podemos suponer que el mensaje, dirigido en primer lugar al pueblo estadunidense, tenía una velada dedicatoria para el Castillo de Chapultepec.

La opinión del cónsul Vázquez fue cambiando a lo largo del periodo abordado. Por primera vez, en noviembre de 1895, hace referencia a la idea de la anexión de Cuba a México calificándola de simpática pero "no hacedera", sin embargo, para no cerrar posibilidades, añade que con el tiempo sería "tan conveniente como realizable". ${ }^{75}$ En marzo de 1896 informa que en la prensa habanera fueron reproducidas las declaraciones del senador estadunidense Sherman quien creía conveniente que la isla formara parte de la federación mexicana ${ }^{76} \mathrm{Al}$ mes siguiente, escribió a Mariscal después de haber recibido una carta recriminatoria de Carlos Américo Lera, a la sazón secretario particular del ministro Mariscal y autor del proyecto de Cuba mexicana, ${ }^{77}$ quien era cubano como don

${ }^{74}$ Matías Romero a Felipe Berriozábal, 9 de diciembre de 1896, AMR, Libros copiadores, $t$. 59, f. 174.

${ }^{75}$ A. C. Vázquez a I. Mariscal, reservada, 26 de noviembre de 1895, AHSREM, exp. 40-2111(III), f. 170.

${ }^{76}$ A. C. Vázquez a I. Mariscal, 5 de marzo de 1896, AHSREM, LE 518, fs. 47-56.

${ }^{77}$ C. A. Lera a A. C. Vázquez, ibid., LE 520, f. 31, y exp. 6-4-96. 
Andrés Clemente y como él naturalizado mexicano. En su nota Vázquez explica su proceder en los círculos oficiales cubanos, es decir, defender absolutamente los intereses mexicanos; aprovechó la oportunidad para expresar su opinión respecto a la propuesta de su antiguo amigo, reconociendo sus deseos recónditos de que Cuba perteneciera a México, pero "no en ese momento". ${ }^{78}$ Mariscal, en su respuesta ni aceptó ni negó el origen de la campaña, sólo le recordó a nuestro cónsul que debía mantener su posición de defensa de la neutralidad mexicana, mientras no se le avisara de nuevos cambios. ${ }^{79}$ Por esos días, marzo de 1896 , llegaron cientos de ejemplares del folleto Cuba mexicana a la isla y las autoridades administrativas preguntaron a Vázquez qué destino darles. Nuestro cónsul decidió -con la posterior aprobación de Mariscal- deslindarse de toda responsabilidad y lo dejó a criterio de las autoridades españolas. ${ }^{80}$ En junio cómentó que la idea de la Confederación Cubana-Mexicana comenzaba a hallar simpatía entre los numerosos españoles residentes en la isla que preferirían que Cuba no cayera en las garras del águila del Potomac, sino que "adquiriendo personalidad y soberanía propias" se uniera a la tierra de Hidalgo. ${ }^{81}$ En noviembre,

${ }^{78}$ A. C. Vázquez a I. Mariscal, 6 de abril de 1896, ibid., fs. 31-55. 77

${ }^{79}$ Mariscal, 10 de abril de 1896 , ibid., fs. 76 -

${ }^{80}$ A. C. Vázquez, 10 de abril de 1896 , e I. Mariscal, 21 de mayo de 1896, ibid., LE 520, fs. 106-111.

${ }^{91}$ A. C. Vázquez a I. Mariscal, reservada, 22 de junio de 1896, ibid., LE 521, f. 38. hablando a título personal, resaltó las ventajas que tendría tal acción. ${ }^{\mathrm{H}}$

En España, Riva Palacio al ser entrevistado había dejado en claro -y así lo transmitió en su correspondenciaque no debían anticiparse juicios puesto que había tres elementos graves en juego: primero, que Cuba fuera independiente; segundo, que los cubanos quisieran anexarse a México y, tercero, que México quisiera que se anexaran. $^{83}$

El asunto de la anexión de Cuba a México había desaparecido paulatinamente de la prensa mexicana y después de anunciarse la fundación del partido Cuba Mexicana, en abril de 1896, prácticamente no se había vuelto a mencionar; fue revivido en la prensa estadunidense en 1897. En su correspondencia, Matías Romero envió un artículo publicado en la American Monthly Review of Reviews en el que se sugería la conveniencia de que Cuba formara parte de la República Mexicana y de que Estados Unidos procurara esa anexión a condición de que se le concediera una estación naval en la isla, lo que tal vez explica por qué se volvió a publicar en esos meses -insistiendo en que era la mejor solución incluso para ese país- ${ }^{84}$ y de nue-

Q2 "He explicado con tacto y de modo confidencial las mutuas ventajas que habría para los mexicanos y los habitantes de Cuba en que se llegase a tal solución y me parece que la idea cunde ya aquí como reguero de pólvora". A. C. Vázquez a I. Mariscal, reservada, 9 de noviembre de 1896, ibid., LE 522, fs. 167-176.

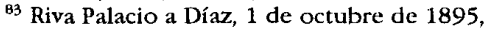
CPD, leg. XX, doc. 15128.

${ }^{84} \mathrm{M}$. Romero a I. Mariscal, AHSREM, LE 529 , fs. $93-94$. 
vo en 1898. Es decir, encubría las intenciones estadunidense. ${ }^{85}$

Mariscal por su parte contestó en una de sus notas a Vázquez que la anexión de Cuba a México, que era de iniciativa extraoficial y debatida por la prensa con toda la libertad y amplitud que garantizaban las leyes, no podía ser reprobada por el gobierno de México

porque entraña una aspiración patriótica y en nada lo compromete; pero tampoco podría el mismo gobierno, mientras no se le propusiera formalmente por las partes directamente interesadas, expresar ninguna opinión respecto a ella, porque el juicio que expresara acerca de su conveniencia sería prematuro y daría lugar a equivocadas interpretaciones. $^{\text {or }}$

Durante 1898 Vázquez no deja de enviar su correspondencia en que transmite sus razonamientos en torno a la conveniencia del interés mexicano. Por ejemplo, al prever la independencia de Cuba bajo protectorado estadunidense y suponer que Estados Unidos ocupa. ría la isla mientras se formara un gobierno de Cuba libre, decía a Mariscal:

ino convendría gestionar con tiempo en la Casa Blanca que de esa junta formara parte un delegado de México como representante de uno de los países más interesados en el porvenir de Cuba?,

e insistía en que, por lo menos, se esforzara en conseguir las ventajas co-

as M. Romero a I. Mariscal, 10 de agosto de 1897 , ibid., LE 529, fs. 76-77, y M. Romero a I. Mariscal, ibid., LE 530, fs. 233-236.

${ }^{86}$ I. Mariscal a A. C. Vázquez, reservada, 16 de abril de 1896 , ibid., LE 520 , f. 56. merciales de la nación más favorecida por 40 o 50 años. ${ }^{87}$

Igual que en los años setenta en los círculos oficiales de México no se creía que Cuba, de obtener su independencia, la pudiera mantener por mucho tiempo sin caer en manos de los estadunidenses ${ }^{88}$ Esta idea la expresa Vázquez en una nota en la que dice "el día que Cuba no sea española, Estados Unidos hará todo lo posible por adjudicársela" ${ }^{89}$ y en otra, comunica a la cancillería que "Cuba y Puerto Rico marchan a pasos precipitados a caer desvanecidos ante el águila de las estrellas y así lo dije a ese departamento de Estado repetidas veces" ${ }^{\prime \prime}$ y añade

${ }^{87}$ A. C. Vázquez a I. Mariscal, reservada, 24 de mayo de 1898 , ibid., LE 526 , f. 200 . En la misma línea meses antes, en octubre de 1897, le había confiado a Mariscal que lo único que habría de lamentar, estando cerca el desenlace de la catástrofe era que su "nación no tomase cartas en el asunto, de acuerdo con el gobierno americano, a fin de recibir ventajas comerciales y políticas en estos territorios, en los instantes de la liquidación, pero confío, para tranquilizarme acerca de este punto, como ardiente mexicano, en las notables y jamás superadits facultades de usted, en la perspicacia diplomática, así como en el concepto atribuido al señor general don Porfirio Díaz, a la llamada Doctrina Monroe". A. C. Vázquez a I. Mariscal, 21 de octubre de 1897, ibid., LE 525, fs. 196-197.

${ }^{a 8}$ En aquel entonces, Pedro Santacilia había escrito que muchos partidarios de la independencia veían con "cierta frialdad la cuestión cubana, imaginando recelosos que al término de la lucha sería inevitable la aparición de la bandera estrellada en las grandes fortalezas que miran desde La Habana las aguas de Veracruz" en Rosen, Santacilia, 1984, p. 251.

${ }^{89}$ A. C. Vázquez a I. Mariscal, 3 de abril de 1896, AHSREM, LE 520, f. 46.

${ }^{90}$ Por ejemplo en enero de 1896 , ibid., LE 532, fs. 87-95. 


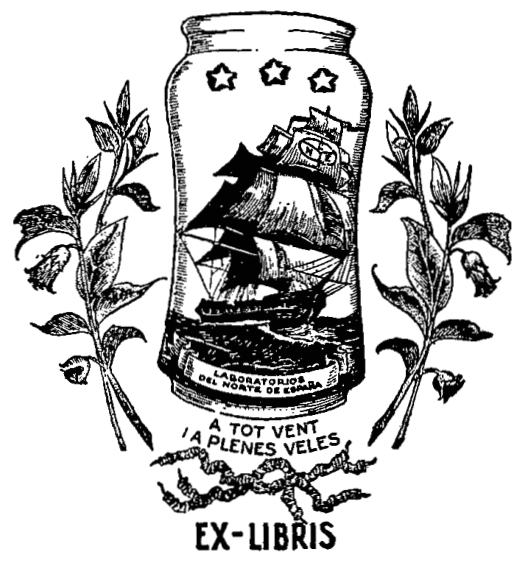

"ojalá que para nuestra patria no traigan estos sucesos funestas consecuencias". ${ }^{11}$ Ya no piensa que México, como una de las potencias de la zona, pueda intervenir en la solución del conflicto. ${ }^{92}$ Mientras, Matías Romero le escribe a Mariscal, "tengo motivos para creer que el gobierno de Estados Unidos se propone conservar en alguna forma a Puerto Rico". 93

91 Vázquez a Mariscal, 26 de julio de 1898 , ibid., LE 526, f. 208.

92 Como pensaba en 1895 cuando le escribió a Mariscal que la situación de Cuba harian necesaria "la intervención armada o diplomática en la isla de Cuba por parte de Estados Unidos y de México, que son las dos potencias más cercanas a ella y que están especialmente interesadas, por lo tanto, en que aquí se restablezca la paz", reservada, 26 de diciembre de 1895 , AGN, Gobernación y Relaciones Exteriores, Libro copiador, 1895-1896, L(729.1-5)-20, f. 62.

${ }^{93}$ Asimismo Matías Romero transmitía la noticia de que al parecer el gobierno español
El 13 de agosto de 1898, el ministro estadunidense en México, Powell Clayton informó a Ignacio Mariscal que con la firma de un protocolo se habían ajustado los preliminares de paz entre España y Estados Unidos "conforme a este arreglo, España abandonó su soberanía en Cuba y desocupó esa isla y cedió a Estados Unidos, Puerto Rico y otras islas de las Antillas [...]" El mismo día Ignacio Mariscal responde de enterado y le comenta que "México celebra la suspensión de hostilidades y desea que la paz se afirme sólidamente entre ambos pueblos". ${ }^{4}$

Con esta información, el gobierno mexicano pudo normar su conducta y desplegar las estrategias que mejor le convinieran en cada momento. Desde el inicio mismo del movimiento independiente en 1895 , declaró que observaría la neutralidad, sin embargo, bajo esa neutralidad oficial, manifestó su simpatía y lazos de amistad al gobierno español al que brindó el apoyo más decidido mientras tuvo la esperanza de que la presencia española en la isla de Cuba pudiera ser un contrapeso al ascenso estadunidense en la región antillana. Asimismo, se permitió mostrar cierta simpatía a los cubanos y a sus seguidores aunque fue, sobre todo, de manera poco definida. En algunas ocasiones manifestó su deseo de ayuda a la cuestión cubana siempre que se encontraran los me-

estaba dispuesto a celebrar la paz bajo la base de reconocer la independencia de Cuba y conceder a Estados Unidos una estación naval en Puerto Rico y otra en Manila. M. Romero a I. Mariscal, AHSREM, LE 530, f. 251.

${ }^{94}$ Diario Oficial, 13 de agosto de 1898. 
dios prudentes y le fuera requerido por las partes involucradas; ofreció su mediación en el conflicto, no impidió -e incluso tal vez alentó- el desarrollo de campañas periodísticas que suscribieron la defensa de una Cuba mexicana o una Cuba española y, finalmente, cuando vio que la causa española estaba perdida, reivindicó radicalmente su neutralidad ${ }^{95}$ Con la posterior contracción de sus actividades e interés en la región se cerró el ciclo que caracterizó la actitud mexicana hacia el Caribe a lo largo del siglo XIX.

\section{CONCLUSIONES}

Frente a la agresividad desplegada por el expansionismo estadunidense, México quiso reformular sus relaciones con su poderoso vecino norteño en términos menos desventajosos. $\mathrm{El} \mathrm{Ca-}$ ribe y la posible influencia que pudiera tener México en la región, principalmente en Cuba, el objetivo más deseado por Estados Unidos, adquirió gran significación en la política mexicana que se jugaba también sus intereses en su frontera sur. Los últimos años del siglo XIX fueron de auge en las relaciones con las islas; esto impulsó el establecimiento de oficinas consulares y viceconsulares, se elevó la categoría de algunos consulados transformándolos en consulados generales y se iniciaron relaciones diplomáticas con la República Dominicana, pero lo más importante fue la posición adoptada por México ante el 1998.

95 Para más detalles véase Muñoz, "México",

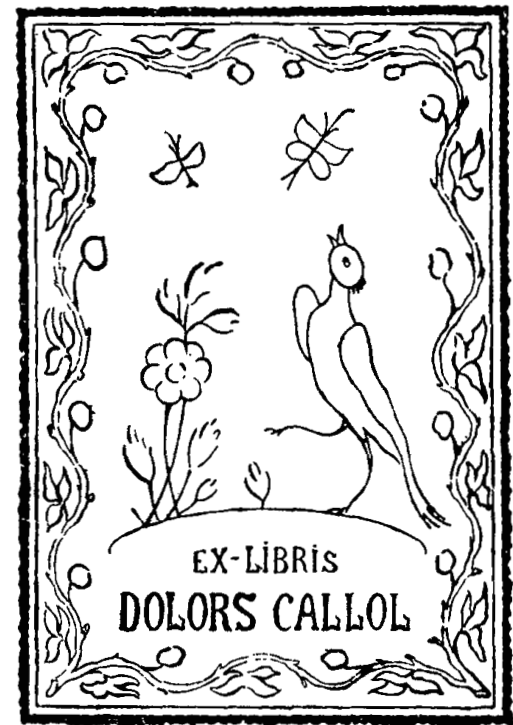

movimiento de independencia cubana iniciado en $1895 .^{96}$

El proceso independentista iniciado en 1895, catalizó todos las actividades e intereses oficiales de México en el área y en función de ello jugó varias estrategias a nivel nacional $\mathrm{e}$ internacional, todas, sin embargo, en un marco de pretendida neutralidad que encubrió, casi hasta que la causa española estuvo perdida, una gran simpatía hacia España. El gobierno mexicano, así como la clase política, estaban conscientes de que en la guerra de Cuba se jugaban intereses que comprometían a toda la región ante la 226.

${ }^{96}$ Véase Muñoz, "Interés", 1996, pp. 217. 
amenaza que significaba el expansionismo estadunidense.

Para normar su conducta y defender mejor sus intereses, el gobierno mexicano contó con toda la información posible generada en los países que intervinieron en el conflicto y que enviaban sus representantes en Estados Unidos, España y Cuba. De la isla salió la mayor cantidad de notas y la transformación en la actitud del cónsul podría llevar a pensar que la posición del gobierno mexicano sufrió los mismos vaivenes - como sostiene Rafael Rojas- pero, aunque el cónsul se esmeró en enviar toda la información y opiniones que creyó convenientes, lo cierto es que sus informes fueron evaluados junto a otros para normar la actitud mexicana en función de la defensa del interés nacional.

Con la intervención estadunidense en Cuba se cerró un ciclo de política mexicana hacia el Caribe, caracterizada por un renovado interés en los acontecimientos que se sucedían en el área y por una mayor presencia en la región a través de la actividad de los consulados y viceconsulados, como respuesta a los movimientos de las metrópolis y en especial al avance de Estados Unidos.

En este periodo la política mexicana en la región estuvo marcada por el avance estadunidense y por la decadencia española como poder imperial. Así que con el fin de la guerra hispano-cubano-estadunidense que marcó el comienzo del poder hegemónico regional de Estados Unidos se dio inicio paralelamente, al retroceso de la política mexicana hasta bien entrado el siglo $\mathrm{XX}$.

\section{ARCHIVOS}

AGN Archivo General de la Nación, ramo Gobernación y Relaciones Exteriores, Libros copiadores de la correspondencia del Consulado de México en La Habana.

AHSREM Archivo Histórico de la Secretaría de Relaciones Exteriores de México, Expedientes personales.

AHSREM- Archivo Histórico de la SecretaAEMEUA ría de Relaciones Exteriores en México, Archivo de la Embajada de México en Estados Unidos de América.

AMR Archivo Matías Romero, Libros copiadores de la correspondencia de la legación de México en Washington, Tratados ratificados por convenios ejecutivos celebrados por México. Senado de la República.

CPD Colección Porfirio Díaz.

\section{HEMEROGRAFÍA}

Diario Oficial, 1898, México. El Nacional, 1895-1898, México. La Patria, 1895-1898, México.

\section{BIBLIOGRAFÍA}

-Abad, José Ramón, La República Dominicana. Reseña general geográfico-estadística, Santo Domingo, 1888.

-Bobadilla, Leticia, "La opinión pública en México frente a la guerra hispano-cubano-americana de 1898", tesis de licenciatura en Historia, FFyL-UNAM, México, 1994.

-Deger, John, "Porfirian foreign policy and mexican nationalism. A study of cooperation and conflict in mexican-american relations 1884-1904" tesis de doctorado, Universidad de Indiana, 1979. 
-Espinosa B., Margarita, "El Caribe en la correspondencia consular mexicana, 1895-1900. El caso del consulado mexicano en La Habana" en AMEI, Seminario Internacional México y sus relaciones con el Caribe, Chetumal, 27.29 de agosto de 1997.

-Espinosa, Margarita, "El proceso independentista cubano desde la perspectiva de El Nacional y El Hijo del Abuizote, 1895-1898", tesis de licenciatura en Historia, UMSNH, México, 1996.

-Gilmore, Ray, "Mexico and the spanishamerican war", Hispanoamerican Historical Review, vol. XLII, núm. 4, noviembre de 1963, pp. 511-525.

-Mahan, Alfred T., The interest of America in sea power. Present and future. Little Brown and Co., Boston, 1918.

-Morales, Salvador, Espacios en disputa. México y la independencia de Cuba, Instituto Tamayo/sRe, México, 1997.

-Muñoz, Laura, "El interés geopolítico de México por el Caribe como espacio regional en el siglo XIX", tesis de doctorado, FCPYS-UNAM, 1996.

, "El interés geopolítico de México por el Caribe en la segunda mitad del siglo XIX", Cuadernos Americanos, nueva época, año $X$, vol. 4, núm. 58 , julioagosto 1996, pp. 217-226.

, "Migración afroantillana a México en el siglo XIX", América Negra, núm. 12, diciembre de 1996, Bogotá, pp. $77-90$.

"El Caribe y México a finales del siglo XIX, 1890-1898", Revista Mexicana del Caribe, Chetumal, año II, núm. 3, enero-junio 1997, pp. 74-111.

, "La política exterior de México ante la guerra de 1898", Revista Mexi- cana del Caribe, año 3, núm. 5, enerojunio de 1998.

México y Cuba: una relación bistórica, Instituto Mora, México, 1998 (Col. Perfiles, serie América Latina). , "México ante la independencia cubana 1895-1898" en Ana Rosa Suárez (comp.), Pragmatismo y principios: la relación conflictiva entre México y Estados Unidos, 1810-1942, Instituto Mora/Conacyt, 1998.

-Pi-Suñer, Antonia, México y Lspaña durante la república restaurada, SRE, México, 1985 (Archivo Histórico Diplomático, 24).

-Pulido, Gabriela, "Aproximaciones a la política exterior del porfiriato. La gestión diplomática de Andrés Clemente Vázquez", tesis de licenciatura en Historia, FFYL-UNAM, 1997.

-Rojas, Rafael, "La política:mexicana ante la guerra de independencia de Cuba (1895-1898)", Historia Mexicana, lil Colegio de México, vol. XLV, núm. 4, abriljunio de 1996, pp. 783-805.

-Rosen, Boris, Pedro Santacilia. Hl bombre y su obra, Instituto Tamayo, México, 1984.

-Rosenzweig, Gabriel, "La colonia española de México y la guerra de Cuba, 18951898", Casino Español de México, Boletín Informativo del Casino Español, año 1, núm. 2, mayo de 1998, México.

-Sánchez, Agustín, "Crisis colonial y política exterior: la política española en el Caribe (1878-1898)", V Congreso de la Asociación Mexicana de Estudios del Caribe, Jalapa, 1-3 de abril de 1998.

-Tratados ratificados y convenios ejecutivos celebrados por México, Senado de la República, México, s.f., t. II. 


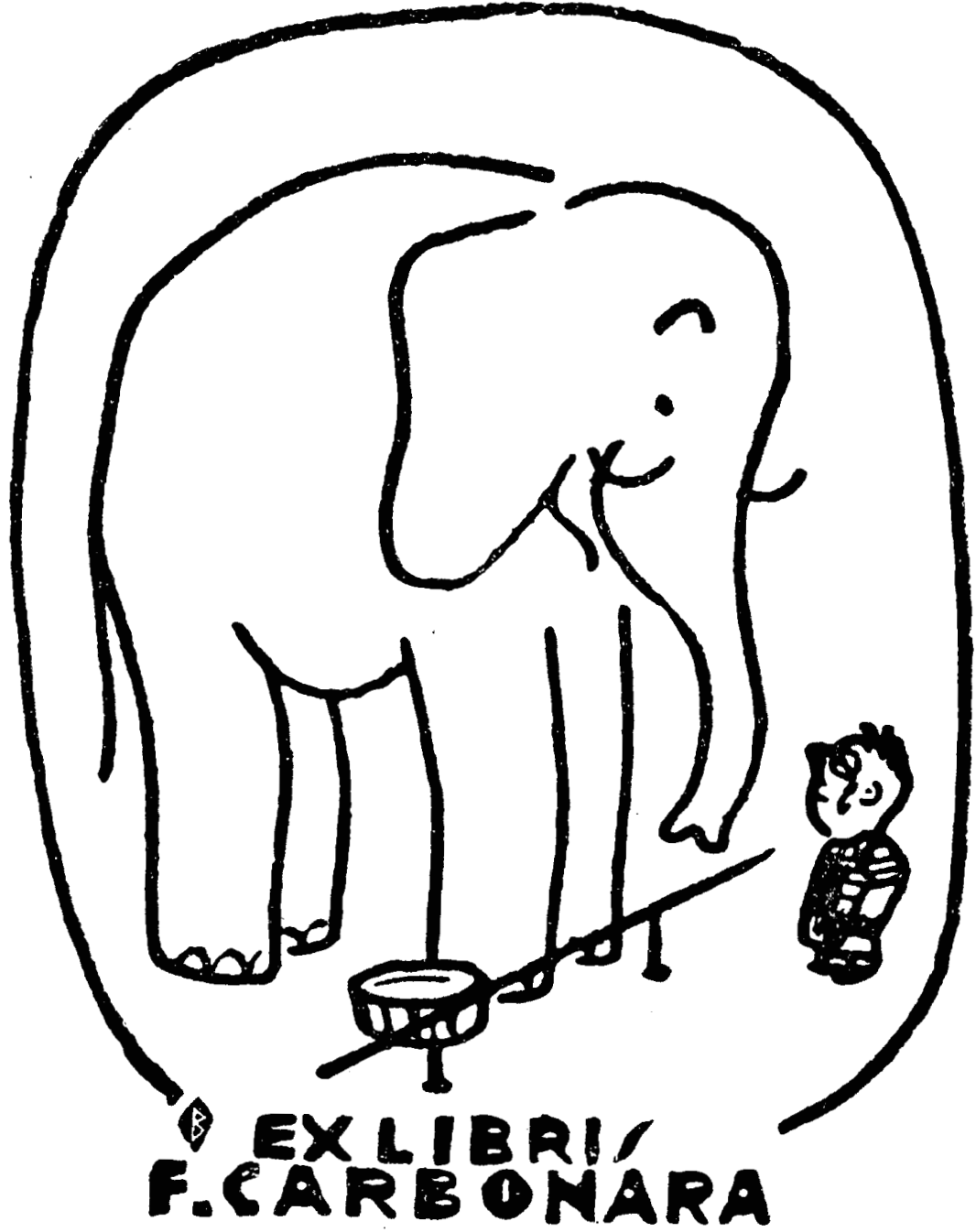

